\title{
Synthesis and SAR Study of Novel Amidino 2-substituted Benzimidazoles as Potential Antibacterial Agents
}

Nataša Perin, ${ }^{1}$ Kristina Starčević, $2, *$ Mihaela Perić, ${ }^{3}$ Hana Čipčić Paljetak, ${ }^{3}$ Mario Matijašić, ${ }^{3}$ Višnja Stepanić, ${ }^{4}$ Donatella Verbanac, ${ }^{3}$ Grace Karminski-Zamola, ${ }^{1}$ Marijana Hranjec ${ }^{1, \#}$

\footnotetext{
${ }^{1}$ Department of Organic Chemistry, Faculty of Chemical Engineering and Technology, University of Zagreb, Marulićev trg 20, P. O. Box 177, HR-10000 Zagreb, Croatia

2 Department of Animal Husbandry, Faculty of Veterinary Medicine, University of Zagreb, Heinzelova 55, HR-10000 Zagreb, Croatia

3 Department for Intercellular Communication, Center for Translational and Clinical Research, University of Zagreb School of Medicine, Šalata 2, HR-10000 Zagreb, Croatia

${ }_{4}$ Division of Molecular Medicine, Laboratory for Epigenomics, Ruđer Bošković Institute, Bijenička cesta 54, HR-10000 Zagreb, Croatia

* Corresponding author's e-mail address: kstarcevic@vef.hr

\# Corresponding author's e-mail address: mhranjec@fkit.hr
}

RECEIVED: May 09, 2017 \ REVISED: June 05, 2017 \ ACCEPTED: June 07, 2017

Abstract: A series of novel 2-substituted benzimidazole derivatives were synthesized and their antibacterial activity was assessed against selected Gram-positive and Gram-negative bacteria. The specific moiety at the 2-position of the benzimidazole was extensively modified with several fused heterocyclic functional groups containing nitrogen and sulfur heteroatoms. In addition, the influence of different amidino groups at the position 5 of benzimidazole scaffold was evaluated. The values of clogP (a partition coefficient) and clog $\mathrm{D}_{7.5}$ (calculated distribution coefficient, $\mathrm{pH}$ 7.5) were determined and the lipophilic character of compounds has been found to be important parameter for the observed activity of the tested benzimidazole derivatives against Moraxella catarrhalis. The indolo 2-substituted benzimidazole 13 a demonstrated solid activity against Staphylococcus aureus (MICs $16 \mu \mathrm{g} / \mathrm{mL}$ ) and Moraxella catarralis (MICs $2 \mu \mathrm{g} / \mathrm{mL}$ ) and represents promising lead molecule for further optimization.

Keywords: amidines, benzimidazoles, antibacterial activity, Moraxella catarrhalis, lipophilicity.

\section{INTRODUCTION}

B ACTERIAL organisms causing infectious diseases represent an increasing public health problem regard less of the current availability of numerous antimicrobial agents. Not only has the incidence of infections caused by resistant bacterial pathogens been continuously increasing during the last decades, but even the formerly commensal species have raised serious health concerns because of dramatic changes in their genetic makeup. This is the case with Moraxella catarrhalis.[1] In recent years, Moraxella catarrhalis has established its position as an important human mucosal pathogen, no longer being regarded as just a commensal bacterium. It has been associated with childhood otitis media (OM) and lower respiratory tract infections in adults with chronic pulmonary disease as a third common bacterial cause after Haemophilus influenzae and Streptococcus pneumoniae. ${ }^{[2]}$ Even though Moraxella catharralis has not been identified as an important human pathogen, it is obvious that it has a significant financial impact on global health care systems.[3] Benzimidazoles displayed a variety of biological effects, such as antihelmintic, ${ }^{[4]}$ antiviral, ${ }^{[5,6]}$ anticancer, ${ }^{[7]}$ anti-inflammatory ${ }^{[8]}$ or antioxidant ${ }^{[9]}$ activities. Consequently, benzimidazole core received attention as an important pharmacophore for the development of novel

(cc) Br 
<smiles>[R]CNC([X])c1ccc2c(c1)nc(-c1c([R])c([R])c([R3])c([R])c1[R])n2[R]</smiles>

$\mathrm{R}^{\prime}=\mathrm{H}$, methyl, $n$-butyl, benzyl, $\mathrm{CH}_{2}$-1-naphtyl

$\mathrm{R}^{\prime \prime}=\mathrm{H}$, isopropyl, cyclopropil, $n$-butyl, isopentyl, cyclohexyl, 2,4-dichlorobenzyl, $\mathrm{CH}_{2}$-1-naphtyl

$\mathrm{R}_{1}=\mathrm{H}, \mathrm{Cl}$

$\mathrm{R}_{2}=\mathrm{H}, \mathrm{Cl}, \mathrm{F}, \mathrm{OCH}_{3}$

$\mathrm{R}_{3}=\mathrm{H}, \mathrm{Cl}, \mathrm{F}, \mathrm{OCH}_{3}, \mathrm{CN}$

$\mathrm{R}_{4}=\mathrm{R}_{5}=\mathrm{H}, \mathrm{Cl}$

Figure 1. Amidino substituted 2-benzimidazoles with antibacterial activity.

antimicrobial agents in inhibiting synthesis of microbial nucleic acids and proteins and preventing the growth of various microorganisms (Figure 1). ${ }^{[10]}$

In addition, there is a trend in the design of novel hybrid antibacterial compounds by combining two or more biologically active heterocyclic pharmacophores in a single molecule. ${ }^{[11-13]}$ The most used heterocycles containing one or two nitrogen atoms have been imidazole, pyridine and pyrrole, and fused scaffolds like benzothiophens, indols, benzothiazoles and quinolines. ${ }^{[14]}$

Furthermore, the amidine moiety is found in a variety of biologically active molecules. ${ }^{[15]}$ The amidine derivatives generally possess broad spectrum of biological activities: anticancer, ${ }^{[16]}$ antimicrobial, ${ }^{[17]}$ anti-HIV[18] and anti-inflammatory. ${ }^{[19,20]}$ The positively charged amidine groups are attracted by electrostatic interactions to negatively charged DNA thus enabling selective binding. [21]

In view of the afore-mentioned findings and in a continuation of our research on biologically active heterocycles, ${ }^{[22-25]}$ we hereby describe the synthesis of a new 2,5(6)-disubstituted benzimidazole derivatives and their evaluation as antibacterial agents. The structure activity relationship of their antibacterial activities was also examinate.

\section{EXPERIMENTAL PART}

\section{Chemistry GENERAL}

Melting points were determined by SMP10 Bibby apparatus and are uncorrected. IR spectra were recorded on FTIR-ATR spectrophotometer. ${ }^{1 \mathrm{H}}$ and ${ }^{13} \mathrm{C}$ NMR spectra were recorded on Bruker AV 300 and Bruker AV 600 spectrometers using TMS as an internal standard in DMSO$d_{6}$. Chemical shifts are reported in ppm (d) relative to TMS. Elemental analyses for carbon, hydrogen, and nitrogen were performed on a Perkin-Elmer 2400 elemental analyzer and a Perkin-Elmer, Series II, CHNS analyzer 2400. All compounds were routinely checked by TLC with Merck silica gel 60F-254 glass plates. The spectroscopic data regarding ${ }^{13} \mathrm{C}$ NMR spectra and elemental analysis are reported in the Supporting Materials.

\section{General method for preparation of amidino substituted benzimidazoles $3 a, b-14 a, b$}

A mixture of equivalent amounts of corresponding 4- $N$ substituted-1,2-phenylenediamine $\mathbf{2 a - 2} \mathbf{b}$, aromatic aldehyde $\mathbf{1 a}-\mathbf{1 l}$ and $p$-benzoquinone in absolute ethanol $(10-15 \mathrm{~mL})$ was stirred at reflux for 4 hours under nitrogen atmosphere. The reaction mixture was cooled to room temperature and resulting product was filtered off and washed with diethylether $(20 \mathrm{~mL})$. After recrystallization from ethanol/diethylether or ethanol, light powders were obtained.

\section{2-(Naphthalen-1-yl)-3H-benzimidazole-5(6)- $\mathrm{N}$ -}

carboxamidine hydrochloride $3 a$. From $0.150 \mathrm{~g}(0.96 \mathrm{mmol})$ naphthalene-1-carboxaldehyde 1a, $0.179 \mathrm{~g}$ (0.96 mmol) 4$\mathrm{N}$-amidino-1,2-phenylenediamine $2 \mathrm{a}$ and $0.106 \mathrm{~g}(0.96$ mmol) $p$-benzoquinone to obtain $0.145 \mathrm{~g}(47 \%)$ of light brown powder; m.p. $>290^{\circ} \mathrm{C} ;{ }^{1} \mathrm{H}$ NMR (DMSO- $d_{6}$ ) $\delta / p p m$ :

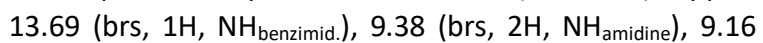
(brs, $2 \mathrm{H}, \mathrm{NH}_{\text {amidine }}$ ), 9.04 (d, $1 \mathrm{H}, J=7.86 \mathrm{~Hz}, \mathrm{H}_{\text {arom. }}$ ), 8.26 (s, $1 \mathrm{H}, \mathrm{H}_{\text {arom. }}$ ), $8.12-8.08\left(\mathrm{~m}, 2 \mathrm{H}, \mathrm{H}_{\text {arom. }}\right), 8.02\left(\mathrm{dd}, 1 \mathrm{H}, J_{1}=7.10\right.$ $\mathrm{Hz}, J_{2}=1.95 \mathrm{~Hz}, \mathrm{H}_{\text {arom. }}$ ), $7.83\left(\mathrm{~d}, 1 \mathrm{H}, J=8.28 \mathrm{~Hz}, \mathrm{H}_{\text {arom. }}\right.$ ), 7.73 (dd, $1 \mathrm{H}, J_{1}=8.42 \mathrm{~Hz}, J_{2}=1.48 \mathrm{~Hz}, \mathrm{H}_{\text {arom. }}$ ), $7.68(\mathrm{~d}, 1 \mathrm{H}, J=7.83$ $\left.\mathrm{Hz}, \mathrm{H}_{\text {arom. }}\right), 7.66-7.57\left(\mathrm{~m}, 2 \mathrm{H}, \mathrm{H}_{\text {arom. }}\right)$.

\section{5(6)-N-(2-Imidazolinyl)-2-(naphthalen-1-yl)-3H-}

benzimidazole hydrochloride $3 b$. From $0.150 \mathrm{~g}(0.96 \mathrm{mmol})$ naphthalene-1-carboxaldehyde 1a, $0.204 \mathrm{~g}$ (0.96 mmol) 4$\mathrm{N}$-(2-imidazolynyl)-1,2-phenylenediamine $\mathbf{2 b}$ and $0.106 \mathrm{~g}$ (0.96 mmol) $p$-benzoquinone to obtain $0.175 \mathrm{~g}(52 \%)$ of light brown powder; m.p. $285-286{ }^{\circ} \mathrm{C} ;{ }^{1} \mathrm{H}$ NMR (DMSO-d $d_{6}$ ) $\delta / p p m: 13.70$ (brs, $1 \mathrm{H}, \mathrm{NH}_{\text {benzimid. }}$ ), 10.78 (brs, $2 \mathrm{H}, \mathrm{NH}_{\text {amidine }}$ ), $9.00\left(\mathrm{~d}, 1 \mathrm{H}, J=8.68 \mathrm{~Hz}, \mathrm{H}_{\text {arom. }}\right), 8.57\left(\mathrm{~s}, 1 \mathrm{H}, \mathrm{H}_{\text {arom. }}\right), 8.17-8.12$ (m, $\left.2 \mathrm{H}, \mathrm{H}_{\text {arom. }}\right), 8.06\left(\mathrm{~d}, 1 \mathrm{H}, J=7.05 \mathrm{~Hz}, \mathrm{H}_{\text {arom. }}\right), 7.95(\mathrm{dt}, 1 \mathrm{H}$, $\left.J_{1}=7.15 \mathrm{~Hz}, J_{2}=1.85 \mathrm{~Hz}, \mathrm{H}_{\text {arom. }}\right), 7.73\left(\mathrm{~d}, 1 \mathrm{H}, J=7.68 \mathrm{~Hz}, \mathrm{H}_{\text {arom. }}\right)$, $7.71\left(\mathrm{~d}, 1 \mathrm{H}, J=7.70 \mathrm{~Hz}, \mathrm{H}_{\text {arom. }}\right), 7.69-7.63\left(\mathrm{~m}, 2 \mathrm{H}, \mathrm{H}_{\text {arom. }}\right.$ ), $4.03\left(\mathrm{~s}, 4 \mathrm{H}, 2 \mathrm{CH}_{2}\right)$.

2-(Quinolin-2-yl)-3H-benzimidazole-5(6)-N-carboxamidine hydrochloride $4 a$. From $0.150 \mathrm{~g}(0.96 \mathrm{mmol})$ quinoline-2carboxaldehyde 1b, $0.179 \mathrm{~g}$ (0.96 mmol) 4- $\mathrm{N}$-amidino-1,2phenylenediamine $2 \mathrm{a}$ and $0.107 \mathrm{~g}(0.96 \mathrm{mmol}) \mathrm{p}$ benzoquinone to obtain $0.220 \mathrm{~g}(47 \%)$ of grey powder; m.p $>290{ }^{\circ} \mathrm{C} ;{ }^{1} \mathrm{H}$ NMR (DMSO-d $d_{6}$ ) $\delta / p p m: 13.74$ (brs, $1 \mathrm{H}$, $\mathrm{NH}_{\text {benzimid.) }}$ ), 9.46 (s, $\left.2 \mathrm{H}, \mathrm{NH}_{\text {amidine }}\right), 9.26$ (s, $2 \mathrm{H}, \mathrm{NH}_{\text {amidine }}$ ), 8.61 (d, $\left.1 \mathrm{H}, J=8.55 \mathrm{~Hz}, \mathrm{H}_{\text {arom. }}\right), 8.50$ (d, $1 \mathrm{H}, J=8.55 \mathrm{~Hz}, \mathrm{H}_{\text {arom. }}$ ), 
$8.27\left(\mathrm{~s}, 1 \mathrm{H}, \mathrm{H}_{\text {arom. }}\right), 8.19$ (d, $1 \mathrm{H}, J=8.43 \mathrm{~Hz}, \mathrm{H}_{\text {arom. }}$ ), 8.10 (d, $\left.1 \mathrm{H}, J=8.36 \mathrm{~Hz}, \mathrm{H}_{\text {arom. }}\right), 7.91\left(\mathrm{dd}, 1 \mathrm{H}, J_{1}=8.56 \mathrm{~Hz}, J_{2}=1.30 \mathrm{~Hz}\right.$, $\mathrm{H}_{\text {arom. }}$ ), 7.87 (dd, $\left.1 \mathrm{H}, J_{1}=8.26 \mathrm{~Hz}, J_{2}=1.24 \mathrm{~Hz}, \mathrm{H}_{\text {arom. }}\right), 7.76$ (d, $\left.1 \mathrm{H}, J=8.26 \mathrm{~Hz}, \mathrm{H}_{\text {arom. }}\right), 7.71\left(\mathrm{dt}, 1 \mathrm{H}, J_{1}=8.10 \mathrm{~Hz}, J_{2}=1.05 \mathrm{~Hz}\right.$, $\mathrm{H}_{\text {arom.). }}$.

5(6)-N-(2-Imidazolinyl)-2-(quinolin-2-yl)-3H-benzimidazole hydrochloride $4 b$. From $0.150 \mathrm{~g}(0.96 \mathrm{mmol})$ quinoline-2carboxaldehyde 1b, $0.203 \mathrm{~g}(0.96 \mathrm{mmol}) \quad 4-\mathrm{N}-(2-$ imidazolynyl)-1,2-phenylenediamine $\mathbf{2 b}$ and $0.107 \mathrm{~g}$ (0.96 mmol) $p$-benzoquinone to obtain $0.240 \mathrm{~g}(52 \%)$ of grey powder; m.p. $>290{ }^{\circ} \mathrm{C} ;{ }^{1} \mathrm{H}$ NMR (DMSO-d $d_{6}$ ) $\delta /$ ppm: 13.82 (brs, $\left.1 \mathrm{H}, \mathrm{NH}_{\text {benzimid. }}\right), 10.74$ (s, 2H, NHamidine) 8.62 (t, $1 \mathrm{H}$, $\left.J=8.61 \mathrm{~Hz}, \mathrm{H}_{\text {arom. }}\right), 8.52\left(\mathrm{~d}, 1 \mathrm{H}, J=8.55 \mathrm{~Hz}, \mathrm{H}_{\text {arom. }}\right), 8.31(\mathrm{~s}, 1 \mathrm{H}$, $\mathrm{H}_{\text {arom. }}$ ), $8.20\left(\mathrm{~d}, 1 \mathrm{H}, J=7.95 \mathrm{~Hz}, \mathrm{H}_{\text {arom. }}\right), 8.11(\mathrm{~d}, 1 \mathrm{H}, J=8.04 \mathrm{~Hz}$, $\mathrm{H}_{\text {arom. }}$ ), $7.98\left(\mathrm{~d}, 1 \mathrm{H}, J=8.10 \mathrm{~Hz}, \mathrm{H}_{\text {arom. }}\right), 7.91$ (dt, $1 \mathrm{H}, J_{1}=8.28$ $\left.\mathrm{Hz}, J_{2}=1.35 \mathrm{~Hz}, \mathrm{H}_{\text {arom. }}\right), 7.82\left(\mathrm{~d}, 1 \mathrm{H}, \mathrm{J}=8.98 \mathrm{~Hz}, \mathrm{H}_{\text {arom. }}\right.$ ), 7.73 (t, $\left.1 \mathrm{H}, \mathrm{J}=7.86 \mathrm{~Hz}, \mathrm{H}_{\text {arom. }}\right), 4.04\left(\mathrm{~s}, 4 \mathrm{H}, 2 \mathrm{CH}_{2}\right.$ ).

2-(Quinolin-3-yl)-3H-benzimidazole-5(6)-N-carboxamidine hydrochloride $5 a$. From $0.100 \mathrm{~g}(0.64 \mathrm{mmol})$ quinoline-3carboxaldehyde 1c, $0.119 \mathrm{~g}$ (0.64 mmol) 4- $\mathrm{N}$-amidino-1,2phenylenediamine $2 \mathrm{a}$ and $0.069 \mathrm{~g}(0.64 \mathrm{mmol}) p$ benzoquinone to obtain $0.135 \mathrm{~g} \mathrm{(65 \% )} \mathrm{of} \mathrm{grey} \mathrm{powder;}$ m.p. 263-265 ${ }^{\circ} \mathrm{C} ;{ }^{1} \mathrm{H}$ NMR (DMSO- $d_{6}$ ) $\delta / p p m: ~ 13.99$ (brs, $\left.1 \mathrm{H}, \mathrm{NH}_{\text {benzimid. }}\right), 9.73$ (d, $\left.1 \mathrm{H}, \mathrm{J}=1.36 \mathrm{~Hz}, \mathrm{H}_{\text {arom. }}\right), 9.36$ (s, $2 \mathrm{H}$, $\left.\mathrm{NH}_{\text {amidine }}\right), 9.21$ (s, $\left.1 \mathrm{H}, \mathrm{H}_{\text {arom. }}\right), 8.98\left(\mathrm{~s}, 2 \mathrm{H}, \mathrm{NH}_{\text {amidine }}\right), 8.30$ (s, $\left.1 \mathrm{H}, \mathrm{H}_{\text {arom. }}\right), 8.15$ (d, $\left.1 \mathrm{H}, J=7.48 \mathrm{~Hz}, \mathrm{H}_{\text {arom. }}\right), 8.14$ (d, $1 \mathrm{H}, J=7.44$ $\left.\mathrm{Hz}, \mathrm{H}_{\text {arom. }}\right), 7.91$ (dd, $\left.1 \mathrm{H}, J_{1}=6.93 \mathrm{~Hz}, J_{2}=1.35 \mathrm{~Hz}, \mathrm{H}_{\text {arom. }}\right), 7.89$ (dd, $1 \mathrm{H}, J_{1}=7.14 \mathrm{~Hz}, J_{2}=1.23 \mathrm{~Hz}, \mathrm{H}_{\text {arom. }}$ ), 7.76 (dd, $1 \mathrm{H}, J_{1}=7.23$ $\mathrm{Hz}, J_{2}=1.05 \mathrm{~Hz}, \mathrm{H}_{\text {arom. }}$ ), 7.74 (dd, $1 \mathrm{H}, J_{1}=7.18 \mathrm{~Hz}, J_{2}=1.15 \mathrm{~Hz}$, $\mathrm{H}_{\text {arom.). }}$.

5(6)-N-(2-Imidazolinyl)-2-(quinolin-3-yl)-3H-benzimidazole hydrochloride $5 b$. From $0.100 \mathrm{~g}(0.64 \mathrm{mmol})$ quinoline-3carboxaldehyde 1c, $0.136 \mathrm{~g} \quad(0.64 \mathrm{mmol}) \quad 4-\mathrm{N}-(2-$ imidazolynyl)-1,2-phenylenediamine $\mathbf{2 b}$ and $0.069 \mathrm{~g}$ (0.64 mmol) $p$-benzoquinone to obtain $0.095 \mathrm{~g}$ (42\%) of light blue powder; m.p. $>290{ }^{\circ} \mathrm{C} ;{ }^{1} \mathrm{H}$ NMR (DMSO- $\left.d_{6}\right) \delta / p p m$ : 14.15 (s, $\left.1 \mathrm{H}, \mathrm{NH}_{\text {benzimid. }}\right), 10.62$ (s, 2H, $\left.\mathrm{NH}_{\text {amidine }}\right), 9.74(\mathrm{~s}, 1 \mathrm{H}$, $\left.\mathrm{H}_{\text {arom. }}\right), 9.24$ (d, $\left.1 \mathrm{H}, J=7.46 \mathrm{~Hz}, \mathrm{H}_{\text {arom. }}\right), 8.47$ (s, $1 \mathrm{H}, \mathrm{H}_{\text {arom. }}$ ), $8.16\left(\mathrm{~d}, 1 \mathrm{H}, J=7.40 \mathrm{~Hz}, \mathrm{H}_{\text {arom. }}\right), 8.14$ (d, $1 \mathrm{H}, J=7.36 \mathrm{~Hz}, \mathrm{H}_{\text {arom. }}$ ), 7.99 (s, $1 \mathrm{H}, \mathrm{H}_{\text {arom. }}$ ), 7.91 (dd, $1 \mathrm{H}, J_{1}=7.10 \mathrm{~Hz}, J_{2}=1.22 \mathrm{~Hz}$, $\mathrm{H}_{\text {arom.) }}$ ), 7.89 (dd, $1 \mathrm{H}, J_{1}=7.16 \mathrm{~Hz}, J_{2}=1.20 \mathrm{~Hz}, \mathrm{H}_{\text {arom. }}$ ), 7.73 (t, $\left.1 \mathrm{H}, \mathrm{J}=7.78 \mathrm{~Hz}, \mathrm{H}_{\text {arom. }}\right), 4.05\left(\mathrm{~s}, 4 \mathrm{H}, 2 \mathrm{CH}_{2}\right)$.

2-(Quinolin-4-yl)-3H-benzimidazole-5(6)-N-carboxamidine hydrochloride $6 a$. From $0.100 \mathrm{~g}(0.64 \mathrm{mmol})$ quinoline-4carboxaldehyde $1 \mathrm{~d}, 0.119 \mathrm{~g}$ (0.64 mmol) 4- $\mathrm{N}$-amidino-1,2phenylenediamine $2 \mathrm{a}$ and $0.069 \mathrm{~g}(0.64 \mathrm{mmol}) \mathrm{p}$ benzoquinone to obtain $0.090 \mathrm{~g}$ (43\%) of light green powder; m.p. $257-259{ }^{\circ} \mathrm{C} ;{ }^{1} \mathrm{H}$ NMR (DMSO- $d_{6}$ ) $\delta / p p m$ : 14.00 (brs, $\left.1 \mathrm{H}, \mathrm{NH}_{\text {benzimid.) }}\right), 9.40$ (s, 2H, NHamidine), 9.25 (d, $\left.1 \mathrm{H}, J=8.43 \mathrm{~Hz}, \mathrm{H}_{\text {arom. }}\right), 9.14\left(\mathrm{~d}, 1 \mathrm{H}, J=4.53 \mathrm{~Hz}, \mathrm{H}_{\text {arom }}\right), 9.09$ (s, $\left.2 \mathrm{H}, \mathrm{NH}_{\text {amidine }}\right), 8.36\left(\mathrm{~s}, 1 \mathrm{H}, \mathrm{H}_{\text {arom. }}\right), 8.17$ (dd, $1 \mathrm{H}, J_{1}=8.40 \mathrm{~Hz}$, $\left.J_{2}=0.68 \mathrm{~Hz}, \mathrm{H}_{\text {arom. }}\right), 8.12\left(\mathrm{~d}, 1 \mathrm{H}, J=4.52 \mathrm{~Hz}, \mathrm{H}_{\text {arom. }}\right), 7.91$ (dd, $1 \mathrm{H}, J_{1}=6.82 \mathrm{~Hz}, J_{2}=1.42 \mathrm{~Hz}, \mathrm{H}_{\text {arom. }}$ ), 7.88 (dd, $1 \mathrm{H}, J_{1}=6.90 \mathrm{~Hz}$, $J_{2}=1.42 \mathrm{~Hz}, \mathrm{H}_{\text {arom. }}$ ), 7.79 (dd, $1 \mathrm{H}, J_{1}=6.82 \mathrm{~Hz}, J_{2}=1.28 \mathrm{~Hz}$,

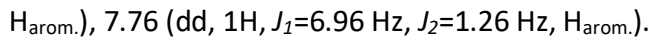

5(6)-N-(2-Imidazolinyl)-2-(quinolin-4-yl)-3H-benzimidazole hydrochloride $6 \mathrm{~b}$. From $0.100 \mathrm{~g}(0.64 \mathrm{mmol})$ quinoline-4carboxaldehyde 1d, $0.136 \mathrm{~g}(0.64 \mathrm{mmol}) \quad 4-\mathrm{N}-(2-$ imidazolynyl)-1,2-phenylenediamine $\mathbf{2 b}$ and $0.069 \mathrm{~g}$ (0.64 mmol) $p$-benzoquinone to obtain $0.055 \mathrm{~g}(40 \%)$ of light yellow powder; m.p. $253-255{ }^{\circ} \mathrm{C}$; ${ }^{1 \mathrm{H}}$ NMR (DMSO-d $d_{6}$ ) $\delta / p p m: 14.03$ (s, $\left.1 \mathrm{H}, \mathrm{NH}_{\text {benzimid. }}\right), 10.59$ (s, 2H, NH $\mathrm{Namidine}_{\text {) }}$, $9.20\left(\mathrm{~d}, 1 \mathrm{H}, J=8.46 \mathrm{~Hz}, \mathrm{H}_{\text {arom. }}\right), 8.59$ (s, $\left.1 \mathrm{H}, \mathrm{H}_{\text {arom. }}\right), 8.15$ (d, $1 \mathrm{H}, J=8.18 \mathrm{~Hz}, \mathrm{H}_{\text {arom. }}$ ), 8.08 (d, $\left.1 \mathrm{H}, J=8.28 \mathrm{~Hz}, \mathrm{H}_{\text {arom. }}\right), 7.95$ (d, $1 \mathrm{H}, J=7.68 \mathrm{~Hz}, \mathrm{H}_{\text {arom. }}$ ), 7.88 (dd, $1 \mathrm{H}, J_{1}=6.98 \mathrm{~Hz}, J_{2}=1.16 \mathrm{~Hz}$, $\mathrm{H}_{\text {arom.) }}, 7.86$ (dd, $1 \mathrm{H}, J_{1}=6.96 \mathrm{~Hz}, J_{2}=1.20 \mathrm{~Hz}, \mathrm{H}_{\text {arom. }}$ ), 7.77 (dd, $1 \mathrm{H}, J_{1}=7.20 \mathrm{~Hz}, J_{2}=1.24 \mathrm{~Hz}, \mathrm{H}_{\text {arom. }}$ ), 7.75 (dd, $1 \mathrm{H}, J_{1}=7.05 \mathrm{~Hz}$, $\left.J_{2}=1.16 \mathrm{~Hz}, \mathrm{H}_{\text {arom. }}\right), 4.03\left(\mathrm{~s}, 4 \mathrm{H}, 2 \mathrm{CH}_{2}\right) \ldots$

\section{2-(Benzo[b]furan-2-yl)-3H-benzimidazole-5(6)-N-}

carboxamidine hydrochloride $7 a$. From $0.150 \mathrm{~g}(1.03 \mathrm{mmol})$ benzo[b]furane-2-carboxaldehyde 1e, $0.192 \mathrm{~g}(1.03 \mathrm{mmol})$ 4- $\mathrm{N}$-amidino-1,2-phenylenediamine $2 \mathrm{a}$ and $0.111 \mathrm{~g}$ (1.03 mmol) $p$-benzoquinone to obtain $0.215 \mathrm{~g}(43 \%)$ of light pink powder; m.p. $228-230{ }^{\circ} \mathrm{C} ;{ }^{1} \mathrm{H}$ NMR (DMSO- $d_{6}$ ) $\delta /$ ppm: 14.10 (s, $\left.1 \mathrm{H}, \mathrm{NH}_{\text {benzimid. }}\right), 9.41$ (s, $\left.2 \mathrm{H}, \mathrm{NH}_{\text {amidine }}\right), 9.14$ (s, $2 \mathrm{H}$, $\mathrm{NH}_{\text {amidine }}$ ), $8.20\left(\mathrm{~s}, 1 \mathrm{H}, \mathrm{H}_{\text {arom. }}\right.$ ), 7.84 (dd, $2 \mathrm{H}, J_{1}=7.83 \mathrm{~Hz}$, $J_{2}=3.57 \mathrm{~Hz}, \mathrm{H}_{\text {arom }}$ ), $7.81\left(\mathrm{~s}, 1 \mathrm{H}, \mathrm{H}_{\text {arom }}\right.$ ), $7.75(\mathrm{~d}, 2 \mathrm{H}, J=7.86$ $\left.\mathrm{Hz}, \mathrm{H}_{\text {arom. }}\right), 7.48\left(\mathrm{t}, 1 \mathrm{H}, \mathrm{J}=8.45 \mathrm{~Hz}, \mathrm{H}_{\text {arom. }}\right), 7.38(\mathrm{t}, 1 \mathrm{H}, \mathrm{J}=8.20$ $\mathrm{Hz}, \mathrm{H}_{\text {arom.). }}$.

\section{5(6)-N-(2-Imidazolinyl)-2-(benzo[b]furan-2-yl)-3H-}

benzimidazole hydrochloride $7 b$. From $0.200 \mathrm{~g}(1.37 \mathrm{mmol})$ benzo[b]furane-2-carboxaldehyde $1 \mathrm{e}, 0.291 \mathrm{~g}(1.37 \mathrm{mmol})$ 4- $\mathrm{N}$-(2-imidazolynyl)-1,2-phenylenediamine $\mathbf{2 b}$ and $0.148 \mathrm{~g}$ (1.37 mmol) $p$-benzoquinone to obtain $0.272 \mathrm{~g}(43 \%)$ of light pink powder; m.p. $>290{ }^{\circ} \mathrm{C} ;{ }^{1} \mathrm{H}$ NMR (DMSO- $d_{6}$ ) $\delta / p p m: 14.11$ (s, $\left.1 \mathrm{H}, \mathrm{NH}_{\text {benzimid. }}\right), 10.80\left(\mathrm{~s}, 2 \mathrm{H}, \mathrm{NH}_{\text {amidine }}\right)$, 8.45 (s, $1 \mathrm{H}, \mathrm{H}_{\text {arom. }}$ ), 7.92 (d, $1 \mathrm{H}, J=7.96 \mathrm{~Hz}, \mathrm{H}_{\text {arom. }}$ ), 7.90 (d, $\left.2 \mathrm{H}, \mathrm{J}=7.92 \mathrm{~Hz}, \mathrm{H}_{\text {arom. }}\right), 7.81\left(\mathrm{~s}, 1 \mathrm{H}, \mathrm{H}_{\text {arom. }}\right), 7.78(\mathrm{~d}, 1 \mathrm{H}, \mathrm{J}=8.44$ $\left.\mathrm{Hz}, \mathrm{H}_{\text {arom. }}\right), 7.48\left(\mathrm{t}, 1 \mathrm{H}, \mathrm{J}=8.20 \mathrm{~Hz}, \mathrm{H}_{\text {arom. }}\right), 7.38(\mathrm{t}, 1 \mathrm{H}, \mathrm{J}=8.14$ $\left.\mathrm{Hz}, \mathrm{H}_{\text {arom. }}\right), 4.07\left(\mathrm{~s}, 4 \mathrm{H}, 2 \mathrm{CH}_{2}\right.$ ).

\section{2-(Benzo[b]thiophen-2-yl)-3H-benzimidazole-5(6)-N-} carboxamidine hydrochloride $8 a$. From $0.200 \mathrm{~g}(1.23 \mathrm{mmol})$ benzo[b]thiophene-2-carboxaldehyde $1 \mathrm{1f}, 0.230 \mathrm{~g}$ (1.23 mmol) 4- $\mathrm{N}$-amidino-1,2-phenylenediamine $2 \mathrm{a}$ and $0.133 \mathrm{~g}$ (1.23 mmol) $p$-benzoquinone to obtain $0.240 \mathrm{~g}(67 \%)$ of light blue powder; m.p. $>290{ }^{\circ} \mathrm{C} ;{ }^{1} \mathrm{H}$ NMR (DMSO- $d_{6}$ ) $\delta / p p m: 14.06$ (s, $\left.1 \mathrm{H}, \mathrm{NH}_{\text {benzimid. }}\right), 9.37$ (s, 2H, $\mathrm{NH}_{\text {amidine }}$ ), 9.08 $\left(\mathrm{s}, 2 \mathrm{H}, \mathrm{NH}_{\text {amidine }}\right), 8.38\left(\mathrm{~s}, 1 \mathrm{H}, \mathrm{H}_{\text {arom. }}\right), 8.18\left(\mathrm{~s}, 1 \mathrm{H}, \mathrm{H}_{\text {arom. }}\right), 8.07$ 
(dd, $1 \mathrm{H}, J_{1}=8.79 \mathrm{~Hz}, J_{2}=3.33 \mathrm{~Hz}, \mathrm{H}_{\text {arom. }}$ ), 7.99 (dd, $1 \mathrm{H}, J_{1}=8.64$ $\mathrm{Hz}, J_{2}=5.30 \mathrm{~Hz}, \mathrm{H}_{\text {arom. }}$ ), 7.80 (d, $2 \mathrm{H}, J=7.84 \mathrm{~Hz}, \mathrm{H}_{\text {arom. }}$ ), 7.70 (d, $2 \mathrm{H}, J=7.60 \mathrm{~Hz}, \mathrm{H}_{\text {arom. }}$ ), $7.47\left(\mathrm{dd}, 1 \mathrm{H}, J_{1}=5.31 \mathrm{~Hz}, J_{2}=3.51\right.$ $\mathrm{Hz}, \mathrm{H}_{\text {arom.). }}$.

5(6)-N-(2-Imidazolinyl)-2-(benzo[b]thiophen-2-yl)-3Hbenzimidazole hydrochloride $8 b$. From $0.150 \mathrm{~g}(0.93 \mathrm{mmol})$ benzo[b]thiophene-2-carboxaldehyde 1f, $0.197 \mathrm{~g}$ (0.93 mmol) 4- $\mathrm{N}$-(2-imidazolynyl)-1,2-phenylenediamine $\mathbf{2 b}$ and $0.100 \mathrm{~g}$ ( $0.93 \mathrm{mmol}) p$-benzoquinone to obtain $0.115 \mathrm{~g}$ (35 $\%)$ of grey powder; m.p. $>290{ }^{\circ} \mathrm{C}$; ${ }^{1} \mathrm{H}$ NMR (DMSO- $d_{6}$ ) $\delta /$ ppm: 14.13 (s, 1H, $\mathrm{NH}_{\text {benzimid. }}$ ), 10.94 (s, 2H, NHamidine), $8.44\left(\mathrm{~s}, 1 \mathrm{H}, \mathrm{H}_{\text {arom }}\right), 8.40\left(\mathrm{~s}, 1 \mathrm{H}, \mathrm{H}_{\text {arom. }}\right), 8.30(\mathrm{~d}, 1 \mathrm{H}, J=8.40$ $\left.\mathrm{Hz}, \mathrm{H}_{\text {arom. }}\right), 8.15$ (d, $\left.1 \mathrm{H}, J=8.36 \mathrm{~Hz}, \mathrm{H}_{\text {arom. }}\right), 8.08$ (d, $1 \mathrm{H}, J=8.10$ $\left.\mathrm{Hz}, \mathrm{H}_{\text {arom. }}\right), 8.00$ (d, $\left.1 \mathrm{H}, J=7.96 \mathrm{~Hz}, \mathrm{H}_{\text {arom. }}\right), 7.91$ (t, $1 \mathrm{H}, J=7.92$ $\mathrm{Hz}, \mathrm{H}_{\text {arom. }}$ ), $7.70\left(\mathrm{t}, 1 \mathrm{H}, \mathrm{J}=7.96 \mathrm{~Hz}, \mathrm{H}_{\text {arom. }}\right.$ ), $4.13\left(\mathrm{~s}, 4 \mathrm{H}, 2 \mathrm{CH}_{2}\right.$ ).

\section{2-(Benzothiazol-2-yl)-3H-benzimidazole-5(6)-N-} carboxamidine hydrochloride 9a. From $0.150 \mathrm{~g}(0.92 \mathrm{mmol})$ benzothiazole-2-carboxaldehyde $1 \mathrm{~g}, 0.172 \mathrm{~g}(0.92 \mathrm{mmol}) 4$ $\mathrm{N}$-amidino-1,2-phenylenediamine $2 \mathrm{a}$ and $0.099 \mathrm{~g}(0.92$ $\mathrm{mmol}) p$-benzoquinone to obtain $0.160 \mathrm{~g}(67 \%)$ of green powder; m.p. $278-280{ }^{\circ} \mathrm{C} ;{ }^{1} \mathrm{H}$ NMR (DMSO- $d_{6}$ ) $\delta /$ ppm: $13.80\left(\mathrm{~s}, 1 \mathrm{H}, \mathrm{NH}_{\text {benzimid. }}\right), 9.45$ (s, 2H, NH $\left.\mathrm{Namidine}\right), 9.12$ (s, 2H, $\mathrm{NH}_{\text {amidine }}$ ), 8.40 (s, $\left.1 \mathrm{H}, \mathrm{H}_{\text {arom. }}\right), 8.12$ (dd, $1 \mathrm{H}, J_{1}=8.40 \mathrm{~Hz}$, $J_{2}=2.40 \mathrm{~Hz}, \mathrm{H}_{\text {arom. }}$ ), 8.08 (dd, $1 \mathrm{H}, J_{1}=8.44 \mathrm{~Hz}, J_{2}=2.44 \mathrm{~Hz}$, $\mathrm{H}_{\text {arom. }}$ ), 7.80 (d, $1 \mathrm{H}, J=7.88 \mathrm{~Hz}, \mathrm{H}_{\text {arom. }}$ ), 7.74 (d, $1 \mathrm{H}, J=7.90 \mathrm{~Hz}$, $\mathrm{H}_{\text {arom. }}$ ), 7.67 (d, $1 \mathrm{H}, \mathrm{J}=8.32 \mathrm{~Hz}, \mathrm{H}_{\text {arom. }}$ ), 7.60 (d, $1 \mathrm{H}, J=8.28 \mathrm{~Hz}$, $\mathrm{H}_{\text {arom.). }}$.

5(6)-N-(2-Imidazolinyl)-2-(benzothiazol-2-yl)-3Hbenzimidazole hydrochloride $9 b$. From $0.150 \mathrm{~g}(0.92 \mathrm{mmol})$ benzothiazole-2-carboxaldehyde $1 \mathrm{~g}, 0.195 \mathrm{~g}$ (0.93 mmol) 4$N$-(2-imidazolynyl)-1,2-phenylenediamine $\mathbf{2 b}$ and $0.099 \mathrm{~g}$ (0.93 mmol) p-benzoquinone to obtain $0.170 \mathrm{~g}$ (35\%) of light grey powder; m.p. $283-385{ }^{\circ} \mathrm{C} ;{ }^{1} \mathrm{H}$ NMR (DMSO- $d_{6}$ ) $\delta /$ ppm: 13.76 (s, $\left.1 \mathrm{H}, \mathrm{NH}_{\text {benzimid. }}\right), 10.32$ (s, 2H, NHamidine), $8.36\left(\mathrm{~s}, 1 \mathrm{H}, \mathrm{H}_{\text {arom. }}\right.$ ), 8.10 (dd, $1 \mathrm{H}, J_{1}=8.44 \mathrm{~Hz}, J_{2}=2.26 \mathrm{~Hz}$, $\mathrm{H}_{\text {arom. }}$ ), 8.02 (dd, $1 \mathrm{H}, J_{1}=8.36 \mathrm{~Hz}, J_{2}=2.30 \mathrm{~Hz}, \mathrm{H}_{\text {arom. }}$ ), 7.77 (d, $\left.1 \mathrm{H}, J=7.90 \mathrm{~Hz}, \mathrm{H}_{\text {arom. }}\right), 7.71\left(\mathrm{~d}, 1 \mathrm{H}, J=7.86 \mathrm{~Hz}, \mathrm{H}_{\text {arom. }}\right), 7.64$ (d, $1 \mathrm{H}, J=8.28 \mathrm{~Hz}, \mathrm{H}_{\text {arom. }}$ ) , $7.58\left(\mathrm{~d}, 1 \mathrm{H}, \mathrm{J}=8.24 \mathrm{~Hz}, \mathrm{H}_{\text {arom. }}\right.$ ), 4.05 (s, $4 \mathrm{H}, 2 \mathrm{CH}_{2}$ ).

2-(Indol-3-yl)-3H-benzimidazole-5(6)-N-carboxamidine hydrochloride $10 a$. From $0.150 \mathrm{~g}(1.03 \mathrm{mmol})$ indole-3carboxaldehyde $\mathbf{1 h}, 0.192 \mathrm{~g}$ (1.03 $\mathrm{mmol}) 4-\mathrm{N}$-amidino-1,2phenylenediamine $2 \mathrm{a}$ and $0.111 \mathrm{~g}(1.03 \mathrm{mmol}) \mathrm{p}$ benzoquinone to obtain $0.155 \mathrm{~g}(48 \%)$ of light brown powder; m.p. $>290^{\circ} \mathrm{C} ;{ }^{1} \mathrm{H}$ NMR (DMSO- $d_{6}$ ) $\delta /$ ppm: 13.37 (s, $\left.1 \mathrm{H}, \mathrm{NH}_{\text {benzimid. }}\right), 11.88\left(\mathrm{~s}, 1 \mathrm{H}, \mathrm{NH}_{\text {ind. }}\right), 9.30\left(\mathrm{~s}, 2 \mathrm{H}, \mathrm{NH}_{\text {amidine }}\right)$, $9.00\left(\mathrm{~s}, 2 \mathrm{H}, \mathrm{NH}_{\text {amidine }}\right), 8.51$ (dd, $1 \mathrm{H}, J_{1}=7.20 \mathrm{~Hz}, J_{2}=2.43 \mathrm{~Hz}$, $\left.H_{\text {arom. }}\right), 8.39$ (s, $\left.1 \mathrm{H}, \mathrm{H}_{\text {arom. }}\right), 8.10\left(\mathrm{~s}, 1 \mathrm{H}, \mathrm{H}_{\text {arom. }}\right), 7.70$ (d, $1 \mathrm{H}$, $J=8.54 \mathrm{~Hz}, \mathrm{H}_{\text {arom. }}$ ), 7.64 (d, $1 \mathrm{H}, J=8.61 \mathrm{~Hz}, \mathrm{H}_{\text {arom. }}$ ), 7.52 (dd, $\left.1 \mathrm{H}, J_{1}=7.36 \mathrm{~Hz}, J_{2}=2.22 \mathrm{~Hz}, \mathrm{H}_{\text {arom. }}\right), 7.27-7.19\left(\mathrm{~m}, 2 \mathrm{H}, \mathrm{H}_{\text {arom. }}\right)$.

5(6)-N-(2-Imidazolinyl)-2-(indol-3-yl)-3H-benzimidazole hydrochloride $10 \mathrm{~b}$. From $0.150 \mathrm{~g}(1.03 \mathrm{mmol})$ indole-3carboxaldehyde $1 \mathrm{~h}, \quad 0.220 \mathrm{~g}(1.03 \mathrm{mmol}) \quad 4-\mathrm{N}-(2-$ imidazolynyl)-1,2-phenylenediamine $\mathbf{2 b}$ and $0.111 \mathrm{~g}$ (1.03 mmol) $p$-benzoquinone to obtain $0.185 \mathrm{~g}(53 \%)$ of dark yellow powder; m.p. $272-274{ }^{\circ} \mathrm{C}$; ${ }^{1} \mathrm{H}$ NMR (DMSO-d $d_{6}$ ) $\delta / p p m: 13.45$ (s, $\left.1 \mathrm{H}, \mathrm{NH}_{\text {benzimid. }}\right), 11.91\left(\mathrm{~s}, 1 \mathrm{H}, \mathrm{NH}_{\text {ind. }}\right), 10.57$ (s, $\left.2 \mathrm{H}, \mathrm{NH}_{\text {amidine }}\right), 8.52$ (dd, $1 \mathrm{H}, J_{1}=7.10 \mathrm{~Hz}, J_{2}=2.25 \mathrm{~Hz}$, $\left.\mathrm{H}_{\text {arom. }}\right), 8.43\left(\mathrm{~s}, 1 \mathrm{H}, \mathrm{H}_{\text {arom. }}\right), 8.31$ (s, $\left.1 \mathrm{H}, \mathrm{H}_{\text {arom. }}\right), 7.82(\mathrm{~d}, 1 \mathrm{H}$, $J=7.96 \mathrm{~Hz}, \mathrm{H}_{\text {arom. }}$ ), 7.53 (dd, $1 \mathrm{H}, J_{1}=7.08 \mathrm{~Hz}, J_{2}=2.40 \mathrm{~Hz}$, $\left.\mathrm{H}_{\text {arom. }}\right), 7.43\left(\mathrm{~d}, 1 \mathrm{H}, J=8.16 \mathrm{~Hz}, \mathrm{H}_{\text {arom. }}\right), 7.28-7.20(\mathrm{~m}, 2 \mathrm{H}$, $\mathrm{H}_{\text {arom. }} 4.02\left(\mathrm{~s}, 4 \mathrm{H}, 2 \mathrm{CH}_{2}\right)$.

\section{2-(Indol-5-yl)-3H-benzimidazole-5(6)- $\mathrm{N}$-carboxamidine} hydrochloride 11a. From $0.100 \mathrm{~g}(0.69 \mathrm{mmol})$ indole-5carboxaldehyde $1 \mathrm{i}, 0.128 \mathrm{~g}$ (0.69 mmol) 4- $\mathrm{N}$-amidino-1,2phenylenediamine $2 \mathrm{a}$ and $0.075 \mathrm{~g}(0.69 \mathrm{mmol}) \mathrm{p}$ benzoquinone to obtain $0.135 \mathrm{~g}$ (63\%) of light violet powder; m.p. $259-260{ }^{\circ} \mathrm{C} ;{ }^{1} \mathrm{H}$ NMR (DMSO- $d_{6}$ ) $\delta / p p m$ : $13.39\left(\mathrm{~s}, 1 \mathrm{H}, \mathrm{NH}_{\text {benzimid. }}\right), 11.44\left(\mathrm{~s}, 1 \mathrm{H}, \mathrm{NH}_{\text {ind. }}\right), 9.28(\mathrm{~s}, 2 \mathrm{H}$, $\left.\mathrm{NH}_{\text {amidine }}\right), 9.00$ (s, $\left.1 \mathrm{H}, \mathrm{H}_{\text {arom. }}\right), 8.47$ (s, 2H, $\left.\mathrm{NH}_{\text {amidine }}\right), 7.66$ (s, $\left.1 \mathrm{H}, \mathrm{H}_{\text {arom. }}\right), 7.65\left(\mathrm{~d}, 1 \mathrm{H}, \mathrm{J}=8.30 \mathrm{~Hz}, \mathrm{H}_{\text {arom. }}\right), 7.56(\mathrm{~d}, 1 \mathrm{H}, J=8.32$ $\mathrm{Hz}, \mathrm{H}_{\text {arom. }}$ ), 7.45 (t, $1 \mathrm{H}, J=2.62 \mathrm{~Hz}, \mathrm{H}_{\text {arom. }}$ ), 6.97 (dd, $1 \mathrm{H}$, $\left.J_{1}=8.37 \mathrm{~Hz}, J_{2}=2.10 \mathrm{~Hz}, \mathrm{H}_{\text {arom. }}\right), 6.90\left(\mathrm{~d}, 1 \mathrm{H}, \mathrm{J}=2.10 \mathrm{~Hz}, \mathrm{H}_{\text {arom. }}\right.$ ), $6.58\left(\mathrm{~d}, 1 \mathrm{H}, \mathrm{J}=8.24 \mathrm{~Hz}, \mathrm{H}_{\text {arom. }}\right.$ ).

5(6)-N-(2-Imidazolinyl)-2-(indol-5-yl)-3H-benzimidazole hydrochloride $11 b$. From $0.100 \mathrm{~g}(0.69 \mathrm{mmol})$ indole-5carboxaldehyde $1 \mathrm{ii}, \quad 0.147 \mathrm{~g} \quad(0.69 \mathrm{mmol}) \quad 4-\mathrm{N}-(2-$ imidazolynyl)-1,2-phenylenediamine $\mathbf{2 b}$ and $0.075 \mathrm{~g}$ (0.69 mmol) $p$-benzoquinone to obtain $0.140 \mathrm{~g}(60 \%)$ of dark yellow powder; m.p. $>290{ }^{\circ} \mathrm{C}$; ${ }^{1} \mathrm{H}$ NMR (DMSO- $d_{6}$ ) $\delta /$ ppm:

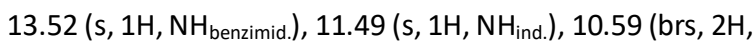
$\left.\mathrm{NH}_{\text {amidine }}\right), 8.52\left(\mathrm{~s}, 1 \mathrm{H}, \mathrm{H}_{\text {arom. }}\right), 8.03\left(\mathrm{~d}, 1 \mathrm{H}, J=8.34 \mathrm{~Hz}, \mathrm{H}_{\text {arom. }}\right.$ ), 7.82 (d, $1 \mathrm{H}, J=8.68 \mathrm{~Hz}, \mathrm{H}_{\text {arom. }}$ ), 7.68 (s, $1 \mathrm{H}, \mathrm{H}_{\text {arom. }}$ ), 7.56 (d, $\left.1 \mathrm{H}, J=8.50 \mathrm{~Hz}, \mathrm{H}_{\text {arom. }}\right), 7.47$ (t, $1 \mathrm{H}, J=2.66 \mathrm{~Hz}, \mathrm{H}_{\text {arom. }}$ ), 7.09 (dd, $1 \mathrm{H}, J_{1}=8.40 \mathrm{~Hz}, J_{2}=2.20 \mathrm{~Hz}, \mathrm{H}_{\text {arom. }}$ ), $6.59(\mathrm{~d}, 1 \mathrm{H}, \mathrm{J}=2.48$ $\left.\mathrm{Hz}, \mathrm{H}_{\text {arom. }}\right), 6.56\left(\mathrm{~d}, 1 \mathrm{H}, \mathrm{J}=8.24 \mathrm{~Hz}, \mathrm{H}_{\text {arom. }}\right), 4.03\left(\mathrm{~s}, 4 \mathrm{H}, 2 \mathrm{CH}_{2}\right.$ ).

2-(2-Methylindol-3-yl)-3H-benzimidazole-5(6)-Ncarboxamidine hydrochloride 12a. From $0.100 \mathrm{~g}(0.63$ $\mathrm{mmol}$ ) 2-methylindole-3-carboxaldehyde $\mathbf{1 j}, 0.117 \mathrm{~g}$ (0.63 mmol) 4- $\mathrm{N}$-amidino-1,2-phenylenediamine $2 \mathrm{a}$ and $0.068 \mathrm{~g}$ (0.63 mmol) p-benzoquinone to obtain $0.105 \mathrm{~g}(52 \%)$ of light violet powder; m.p. $252-254{ }^{\circ} \mathrm{C} ;{ }^{1} \mathrm{H}$ NMR (DMSO- $d_{6}$ ) $\delta / p p m: 12.80$ (s, 1H, $\left.\mathrm{NH}_{\text {benzimid. }}\right), 11.86\left(\mathrm{~s}, 1 \mathrm{H}, \mathrm{NH}_{\text {ind. }}\right.$ ), 9.31 (s, $2 \mathrm{H}, \mathrm{NH}_{\text {amidine }}$ ), 9.03 (s, 2H, $\mathrm{NH}_{\text {amidine }}$ ), 8.17 (dd, $1 \mathrm{H}, J_{1}=7.96$ $\mathrm{Hz}, \mathrm{J}_{2}=2.20 \mathrm{~Hz}, \mathrm{H}_{\text {arom. }}$ ), 8.16 (s, $1 \mathrm{H}, \mathrm{H}_{\text {arom. }}$ ), 7.76 (d, $1 \mathrm{H}, J=8.52$ $\left.\mathrm{Hz}, \mathrm{H}_{\text {arom. }}\right), 7.66$ (dd, $\left.1 \mathrm{H}, J_{1}=8.28 \mathrm{~Hz}, J_{2}=1.50 \mathrm{~Hz}, \mathrm{H}_{\text {arom. }}\right), 7.41$ (dd, $1 \mathrm{H}, J_{1}=7.96 \mathrm{~Hz}, J_{2}=2.10 \mathrm{~Hz}, \mathrm{H}_{\text {arom }}$ ), 7.19-7.14 (m, $2 \mathrm{H}$, $\mathrm{H}_{\text {arom. }),} 2.82\left(\mathrm{~s}, 3 \mathrm{H}, \mathrm{CH}_{3}\right.$ ). 
5(6)-N-(2-Imidazolinyl)-2-(2-methylindol-3-yl)-3Hbenzimidazole hydrochloride $\mathbf{1 2 b}$. From $0.100 \mathrm{~g}(0.63$ mmol) 2-methylindole-3-carboxaldehyde $1 \mathrm{j}, 0.134 \mathrm{~g}$ (0.63 mmol) 4- $\mathrm{N}$-(2-imidazolynyl)-1,2-phenylenediamine $\mathbf{2 b}$ and $0.068 \mathrm{~g}(0.63 \mathrm{mmol}) p$-benzoquinone to obtain $0.068 \mathrm{~g}$ (31 \%) of dark yellow powder; m.p. $278-280{ }^{\circ} \mathrm{C}$; ${ }^{1 \mathrm{H}} \mathrm{NMR}$ (DMSO- $d_{6}$ ) $\delta / \mathrm{ppm}: 12.97$ (s, 1H, $\mathrm{NH}_{\text {benzimid. }),} 11.91$ (s, $1 \mathrm{H}$ $\left.\mathrm{NH}_{\text {ind. }}\right), 10.60$ (s, 2H, NHamidine), 8.31 (s, $\left.1 \mathrm{H}, \mathrm{H}_{\text {arom. }}\right), 8.14$ (dd, $\left.1 \mathrm{H}, J_{1}=8.66 \mathrm{~Hz}, J_{2}=1.60 \mathrm{~Hz}, \mathrm{H}_{\text {arom. }}\right), 7.85\left(\mathrm{dd}, 1 \mathrm{H}, J_{1}=8.60 \mathrm{~Hz}\right.$, $\left.J_{2}=1.44 \mathrm{~Hz}, \mathrm{H}_{\text {arom. }}\right), 7.78\left(\mathrm{~d}, 1 \mathrm{H}, J=8.60 \mathrm{~Hz}, \mathrm{H}_{\text {arom. }}\right), 7.46-7.41$ (m, $\left.1 \mathrm{H}, \mathrm{H}_{\text {arom. }}\right), 7.21-7.15\left(\mathrm{~m}, 1 \mathrm{H}, \mathrm{H}_{\text {arom. }}\right), 4.02\left(\mathrm{~s}, 4 \mathrm{H}, 2 \mathrm{CH}_{2}\right)$, $2.83\left(\mathrm{~s}, 3 \mathrm{H}, \mathrm{CH}_{3}\right)$.

2-(N-Methylindol-3-yl)-3H-benzimidazole-5(6)-Ncarboxamidine hydrochloride 13a. From $0.100 \mathrm{~g}(0.63$ mmol) $\mathrm{N}$-methylindole-3-carboxaldehyde 1k, $0.117 \mathrm{~g}(0.63$ mmol) 4- $\mathrm{N}$-amidino-1,2-phenylenediamine $2 \mathrm{a}$ and $0.068 \mathrm{~g}$ (0.63 mmol) p-benzoquinone to obtain $0.055 \mathrm{~g} \mathrm{(27 \% )} \mathrm{of}$ light brown powder; m.p. 279-281 ${ }^{\circ} \mathrm{C} ;{ }^{1} \mathrm{H}$ NMR (DMSO- $d_{6}$ ) $\delta /$ ppm: 13.53 (s, 1H, $\mathrm{NH}_{\text {benzimid.) }}$ ) 9.33 (s, 2H, $\left.\mathrm{NH}_{\text {amidine }}\right), 9.01$ ( $\left.\mathrm{s}, 2 \mathrm{H}, \mathrm{NH}_{\text {amidine }}\right), 8.53\left(\mathrm{~d}, 1 \mathrm{H}, \mathrm{J}=7.30 \mathrm{~Hz}, \mathrm{H}_{\text {arom. }}\right), 8.37(\mathrm{~s}, 1 \mathrm{H}$, $\left.\mathrm{H}_{\text {arom. }}\right), 8.12\left(\mathrm{~s}, 1 \mathrm{H}, \mathrm{H}_{\text {arom. }}\right), 7.74\left(\mathrm{~d}, 1 \mathrm{H}, J=8.52 \mathrm{~Hz}, \mathrm{H}_{\text {arom. }}\right.$ ), 7.67 (dd, $1 \mathrm{H}, J_{1}=8.34 \mathrm{~Hz}, J_{2}=1.16 \mathrm{~Hz}, \mathrm{H}_{\text {arom. }}$ ), 7.60 (d, $1 \mathrm{H}$, $\left.J=7.44 \mathrm{~Hz}, \mathrm{H}_{\text {arom. }}\right), 7.34\left(\mathrm{t}, 1 \mathrm{H}, J=7.36 \mathrm{~Hz}, \mathrm{H}_{\text {arom. }}\right), 7.29(\mathrm{t}, 1 \mathrm{H}$, $\left.J=7.24 \mathrm{~Hz}, \mathrm{H}_{\text {arom. }}\right)$, $3.94\left(\mathrm{~s}, 3 \mathrm{H}, \mathrm{CH}_{3}\right)$.

5(6)-N-(2-Imidazolinyl)-2-(N-methylindol-3-yl)-3Hbenzimidazole hydrochloride 13b. From $0.100 \mathrm{~g}(0.63$ mmol) $\mathrm{N}$-methylindole-3-carboxaldehyde $1 \mathrm{j}, 0.134 \mathrm{~g}$ (0.63 mmol) 4- $N$-(2-imidazolynyl)-1,2-phenylenediamine $\mathbf{2 b}$ and $0.068 \mathrm{~g}$ (0.63 mmol) $p$-benzoquinone to obtain $0.120 \mathrm{~g}$ (31 \%) of dark yellow powder; m.p. $248-250{ }^{\circ} \mathrm{C}$; ${ }^{1} \mathrm{H}$ NMR

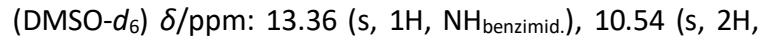
$\mathrm{NH}_{\text {amidine }}$ ), 8.52 (d, $\left.1 \mathrm{H}, J=7.53 \mathrm{~Hz}, \mathrm{H}_{\text {arom. }}\right), 8.33$ (s, $1 \mathrm{H}, \mathrm{H}_{\text {arom. }}$ ), 8.29 (s, $1 \mathrm{H}, \mathrm{H}_{\text {arom. }}$ ), 7.80 (d, $1 \mathrm{H}, J=8.53 \mathrm{~Hz}, \mathrm{H}_{\text {arom. }}$ ), 7.75 (d, $\left.1 \mathrm{H}, J=8.54 \mathrm{~Hz}, \mathrm{H}_{\text {arom. }}\right), 7.58\left(\mathrm{~d}, 1 \mathrm{H}, J=7.53 \mathrm{~Hz}, \mathrm{H}_{\text {arom. }}\right.$ ), 7.32 (dt, $1 \mathrm{H}, J_{1}=7.63 \mathrm{~Hz}, J_{2}=1.24 \mathrm{~Hz}, \mathrm{H}_{\text {arom. }}$ ), 7.27 (dt, $1 \mathrm{H}, J_{1}=7.64$ $\left.\mathrm{Hz}, J_{2}=1.20 \mathrm{~Hz}, \mathrm{H}_{\text {arom. }}\right), 4.02\left(\mathrm{~s}, 4 \mathrm{H}, 2 \mathrm{CH}_{2}\right), 3.93\left(\mathrm{~s}, 3 \mathrm{H}, \mathrm{CH}_{3}\right)$.

\section{2-(N-Acethylindol-3-yl)-3H-benzimidazole-5(6)-N-}

carboxamidine hydrochloride 14a. From $0.100 \mathrm{~g}(0.53$ mmol) $\mathrm{N}$-acethylindole-3-carboxaldehyde $1 \mathrm{l}, 0.100 \mathrm{~g}(0.53$ mmol) 4- $N$-amidino-1,2-phenylenediamine $2 \mathrm{a}$ and $0.057 \mathrm{~g}$ (0.53 mmol) $p$-benzoquinone to obtain $0.099 \mathrm{~g}(53 \%)$ of grey powder; m.p. $249-251^{\circ} \mathrm{C} ;{ }^{1} \mathrm{H}$ NMR (DMSO- $d_{6}$ ) $\delta /$ ppm: 13.73 (s, $\left.1 \mathrm{H}, \mathrm{NH}_{\text {benzimid. }}\right), 9.36$ (s, 2H, NH amidine), 9.04 (s, 2H, $\left.\mathrm{NH}_{\text {amidine }}\right), 9.03\left(\mathrm{~s}, 1 \mathrm{H}, \mathrm{H}_{\text {arom. }}\right), 8.66-8.63\left(\mathrm{~m}, 1 \mathrm{H}, \mathrm{H}_{\text {arom. }}\right)$, 8.43-8.40 (m, $\left.1 \mathrm{H}, \mathrm{H}_{\text {arom. }}\right), 8.21\left(\mathrm{~s}, 1 \mathrm{H}, \mathrm{H}_{\text {arom. }}\right), 7.82(\mathrm{~d}, 1 \mathrm{H}$, $\left.J=8.20 \mathrm{~Hz}, \mathrm{H}_{\text {arom. }}\right), 7.71\left(\mathrm{~d}, 1 \mathrm{H}, J=8.48 \mathrm{~Hz}, \mathrm{H}_{\text {arom. }}\right), 7.48-7.41$ (m, $\left.2 \mathrm{H}, \mathrm{H}_{\text {arom. }}\right), 2.78\left(\mathrm{~s}, 3 \mathrm{H}, \mathrm{OCH}_{3}\right)$.

5(6)-N-(2-Imidazolinyl)-2-(N-acethylindol-3-yl)-3Hbenzimidazole hydrochloride $14 b$. From $0.074 \mathrm{~g}(0.40$ mmol) $N$-acethylindole-3-carboxaldehyde $1 \mathbf{k}, 0.074$ g (0.40 mmol) 4- $N$-(2-imidazolynyl)-1,2-phenylenediamine $\mathbf{2 b}$ and $0.043 \mathrm{~g}$ ( $0.40 \mathrm{mmol}) p$-benzoquinone to obtain $0.065 \mathrm{~g}$ (43 $\%)$ of yellow powder; m.p. $269-271{ }^{\circ} \mathrm{C}$; ${ }^{1} \mathrm{H}$ NMR (DMSO- $d_{6}$ ) $\delta / p p m: 13.81$ (s, $\left.1 \mathrm{H}, \mathrm{NH}_{\text {benzimid. }}\right), 10.62$ (s, 2H, $\mathrm{NH}_{\text {amidine }}$ ), $9.02\left(\mathrm{~s}, 1 \mathrm{H}, \mathrm{H}_{\text {arom. }}\right), 8.63\left(\mathrm{~d}, 1 \mathrm{H}, \mathrm{J}=8.48 \mathrm{~Hz}, \mathrm{H}_{\text {arom. }}\right), 8.43-8.40$ $\left(\mathrm{m}, 1 \mathrm{H}, \mathrm{H}_{\text {arom. }}\right), 8.35$ (s, $\left.1 \mathrm{H}, \mathrm{H}_{\text {arom. }}\right), 7.89(\mathrm{~d}, 1 \mathrm{H}, \mathrm{J}=8.36 \mathrm{~Hz}$,

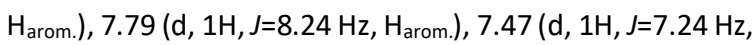
$\mathrm{H}_{\text {arom. }}$ ), 7.44 (d, $\left.1 \mathrm{H}, J=7.12 \mathrm{~Hz}, \mathrm{H}_{\text {arom. }}\right), 4.04\left(\mathrm{~s}, 4 \mathrm{H}, 2 \mathrm{CH}_{2}\right.$ ), $2.78\left(\mathrm{~s}, 3 \mathrm{H}, \mathrm{OCH}_{3}\right)$.

\section{Antibacterial Activity}

Determination of minimal inhibitory concentrations (MICs) was performed according to guidelines of the Clinical Laboratory Standards Institute. [26] Testing was performed by the standard broth microdilution method with azithromycin as the reference antibiotic. Bacterial strains used as the primary screening panel included two strains of Gram-negative species, Esherichia coli (TolC-) (efflux pump deficient strain ECM1556 tolC:Tn10) ${ }^{[27]}$ and Moraxella catarrhalis (ATCC 23246), and two fully sensitive strains of Gram-positive species Staphylococcus aureus (ATCC 29213) and Enterococcus faecalis (ATCC 29212). Bacteria were grown on appropriate agar plates: Mueller-Hinton agar with $5 \%$ sheep blood for enterococci and Moraxella catarrhalis and Mueller Hinton agar for staphylococci and E. coli. Compounds were tested as double dilutions (concentration range $128-0.25 \mu \mathrm{g} / \mathrm{ml}$ ) in 96-well microtitre plates. Bacterial inocula were prepared by direct colony suspension method and plates inoculated with $5 \times 10^{4}$ $\mathrm{cfu} /$ well. Results were determined by visual read-out after overnight incubation at $37^{\circ} \mathrm{C}$ in ambient air.

\section{In Silico}

Predictions of plausible biological targets and pharmacological activities were made by web-service PASS (http://www.pharmaexpert.ru/passonline/index.php) which is based on the identification of substructure features typical for active molecules.[28,29] Lipophilicity parameters clogP and $\operatorname{cog} \mathrm{D}$ at $\mathrm{pH} 7.5$ for synthesized compounds were calculated using Volsurf+ approach. ${ }^{[30]}$ Classification models were built using decision tree algorithm See5, release 2.07.[31]

\section{RESULTS AND DISCUSSION}

\section{Chemistry}

In order to extend biological evaluation of compounds from this class we synthesized new amidino substituted benzimidazoles according to Scheme 1 . The synthesis of 3,4-benzamidines ( $\mathbf{2} \mathbf{a}-\mathbf{2} \mathbf{b}$ ) was performed according to the previously published synthetic procedure, ${ }^{[22]}$ in the acidic Pinner reaction. Further, the novel benzimidazoles outlined 


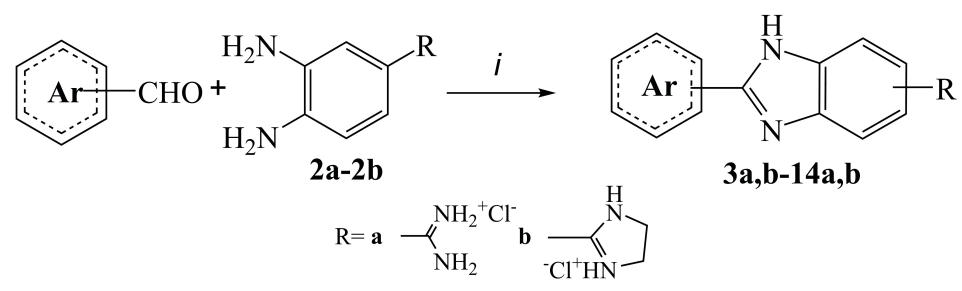

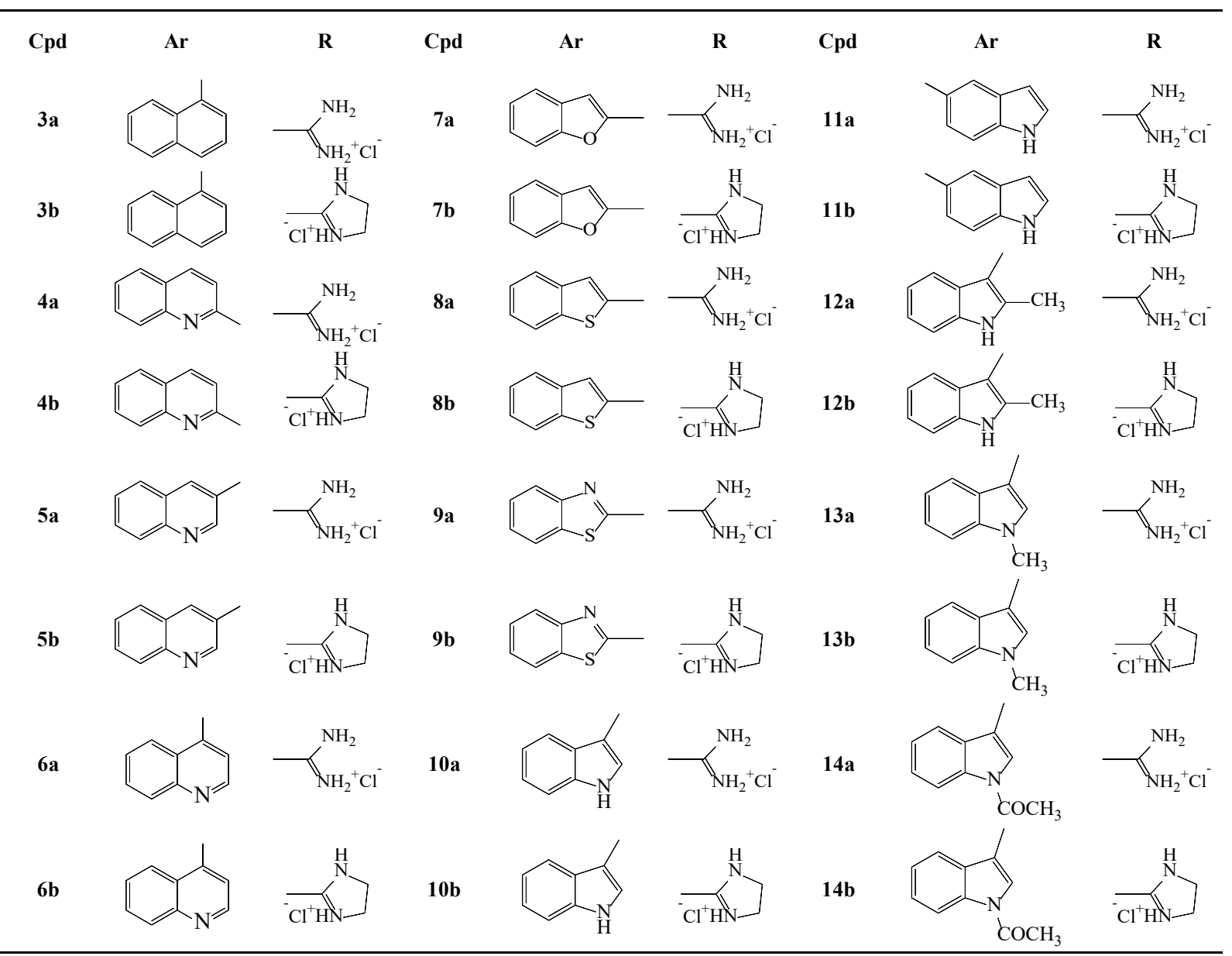

Scheme 1. Reagents and condition: (i) 1,4-benzoquinone, $\mathrm{C}_{2} \mathrm{H}_{5} \mathrm{OH}_{\text {abs., reflux. }}$

in Scheme 1 were synthesized by oxidative coupling of aromatic aldehydes (1a-1) with 3,4-diaminobenzamidines (2a-2b). As already mentioned, the synthesis and biological evaluation of $\mathbf{1 5 a , b - 1 7 a , b}$ was accomplished as previously reported (Figure 2). ${ }^{[22]}$

Amidino substituted benzimidazoles $\mathbf{1 5 a , b - 1 7 a , b}$ were obtained in the cyclocondensation between the aromatic aldehydes and 4-amidino/(2-imidazolinyl)-1,2phenylenediamines hydrochlorides 21-22 with $p$ benzoquinone as oxidizing reagent in absolute ethanol with moderate yields.

The structures of all newly prepared derivatives were determined by using ${ }^{1} \mathrm{H}$ and ${ }^{13} \mathrm{C}$ NMR spectroscopy and elemental analysis. NMR analysis was based on the values of $\mathrm{H}-\mathrm{H}$ coupling constants and chemical shifts in the ${ }^{1} \mathrm{H}$ and ${ }^{13} \mathrm{C}$ NMR spectra.

\section{In Silico Analysis, Antibacterial Activity and Structure Activity Relationship (SAR)}

Biological potential of synthesized compounds (Scheme 1 and Figure 2) were estimated using Prediction of Activity Spectra for Substances (PASS) via web service. PASS is widely utilized for prediction of pharmacotherapeutic effects and biological targets of drug-like compounds. ${ }^{[30,31]}$ The estimates are based on the SAR analysis of known compounds with experimentally established biological 

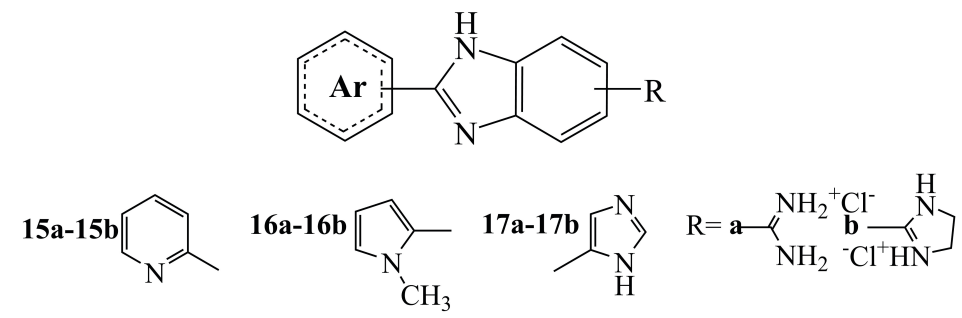

Figure 2 . Benzimidazole derivatives previously prepared $15 a, b-17 a, b$.

activity spectra. The predicted activity spectrum is presented in PASS by the list of activities with the probabilities 'to be active' $(\mathrm{Pa})$ calculated for each activity. ${ }^{[28-30,32]}$ The probability, $\mathrm{Pa}$, reflects the similarity of a molecule under prediction with the structures of molecules, which are the most typical in a sub-set of 'actives' in the structure-activity relationship (SAR) PASS database. According to the PASS output the synthetized compounds could potentially act as omptin inhibitors ( $\mathrm{Pa} \geq$ 0.5). Omptins represent a unique group of integral outer membrane (OM) proteases implicated in pathogenicity and are present in a number of gram-negative pathogens. Because of their direct involvement in pathogenesis, omptins are prime candidates for therapeutic targeting. ${ }^{[33]}$ According to these predicted results we tested the in vitro antibacterial activity of novel 2,5(6)-disubstituted benzimidazole derivatives $\mathbf{3 a , b - 1 7 a , b}$ against gram-negative bacteria Escherichia coli (TolC-) and Moraxella catarrhalis (ATCC 23246). In addition, the in vitro antibacterial activity against gram-positive bacteria including Staphylococcus aureus (ATCC 29213) and Enterococcus faecalis (ATCC29212) was evaluated. The minimal inhibitory concentrations (MICs) of the newly synthesized compounds $\mathbf{3 a , b - 1 7 a , b}$ and of the standard antibiotic azithromycin against all bacterial strains were determined and are presented in Table 1. Structural modifications at position 2 of benzimidazole have included various aromatic fragments (Ar: pyrrole, pyridine, naphthalene, quinoline, benzothiazole, benzofurane, benzothiophene and indole) and at position 5 two types of end groups (R: un-substituted amidine and cyclic amidines) (Scheme 1).

The antibacterial testing demonstrated that variation of the fused heterocycles nuclei at position 2 of benzimidazole had significant impact on selectivity and activity towards different bacterial species (Table 1). In general, all tested compounds showed weak to moderate activity towards tested bacteria with the exception of activity against Moraxella catarrhalis against which tested compounds showed the highest potency. The most active compounds (5a-b, 8a, 10a-b, 11a, 13a-b, 14a-b) exhibited activity against Moraxella catarrhalis in the range of 2-4 $\mu \mathrm{g} / \mathrm{mL}$. These compounds have a substituent containing fused benzene ring and six of them have indole ring bonded to benzimidazole at position 3 . The activities of molecules 10a-b, 13a-b and 14a-b, were not affected by substituents at $\mathrm{N}-1$ of indole or the type of amidino/imidazolinyl group at $\mathrm{C}-5$ of benzimidazole. The compound 13a also displayed acceptable antibacterial activity towards Staphylococcus aureus (MIC value $16 \mu \mathrm{g} / \mathrm{mL}$ ), indicating its potential for further development as a broad-spectrum antibacterial. Among indole substituted benzimidazoles, the best activity was observed for derivatives with indole bonded at their position 3 to benzimidazole.

In addition to activity against Moraxella catarralis, the benzothiophene derivative (8a) also showed moderate activity towards gram-positive bacterial strains, Staphylococcus aureus and and Enterococcus faecalis, with MICs values 16 and $32 \mu \mathrm{g} / \mathrm{mL}$, respectively (Table 1 ). Similarly, benzothiazole derivatives $(\mathbf{9 a}-\mathbf{b})$ were also active against Enterococcus faecalis (MIC 32 and $64 \mu \mathrm{g} / \mathrm{mL}$, respectively) and Escherichia coli (MIC of $8 \mu \mathrm{g} / \mathrm{mL}$ ). These three indole derivatives have shown the broadest spectrum of activity against the tested bacterial strains. In comparison to molecules with heterocycles containing fused benzene ring, the com-pounds 15ab, $16 \mathbf{a}-\mathbf{b}$ and $17 \mathbf{a}-\mathbf{b}$, were generally less active against Moraxella catarrhalis as well as other three tested strains (Table 1). The substitution of pyrrole fragment with the indole moiety, lead to 2-8 fold increase of the antibacterial activity against Moraxella catarrhalis. Moreover, the activity towards gram positive bacteria, especially against Staphylococcus aureus was also increased by this structural modification. In contrast to the compounds comprising indole and heterocycles with sulphur, derivatives containing other heterocycles with fused benzene ring such as na-phthalene, (3a-b), quinoline (4a-b), bezofuran (7a-b) had moderate activity against Moraxella catarrhalis (MICs $8-16 \mu \mathrm{g} / \mathrm{mL}$ ).

Additionally, our compound design also included structural modifications of the amidine moiety as our previous experience with un-substituted amidines and cyclic amidines revealed pharmacologically relevant analogues with prominent biological activity. ${ }^{[22,33]}$

Furthermore, it was previously shown that positively charged terminal groups are responsible for accumulation into cells. ${ }^{[34,35]}$ Here presented pairs of acyclic and cyclic amidine derivatives have shown almost identical activities against all examined bacterial species. 
Table 1. $C \log P / \log D$ Values and minimal inhibitory concentrations (MICs) determined against four bacterial strains

\begin{tabular}{|c|c|c|c|c|c|}
\hline \multirow{2}{*}{ Cpd } & \multirow{2}{*}{$\mathrm{cLog} P / \log \mathrm{D}_{7.5} *$} & \multicolumn{4}{|c|}{$\operatorname{MICs}(\mu g / m L)$} \\
\hline & & S. aureus & E. faecalis & E. coli & M. catarrhalis \\
\hline $3 a$ & $3.45 / 1.84$ & 64 & 32 & 128 & 8 \\
\hline $3 b$ & $3.73 / 2.15$ & 64 & 64 & 128 & 8 \\
\hline $4 a$ & $2.7 / 0.95$ & 64 & 32 & 128 & 8 \\
\hline $4 b$ & $2.98 / 1.82$ & $>128$ & 64 & 128 & 16 \\
\hline $5 a$ & $2.56 / 2.07$ & 128 & 64 & 128 & 4 \\
\hline $5 b$ & $2.84 / 1.33$ & 32 & 32 & 64 & 4 \\
\hline $6 a$ & $2.49 / 0.73$ & 128 & 128 & $>128$ & 8 \\
\hline $6 b$ & $2.77 / 1.59$ & 128 & $>128$ & $>128$ & 16 \\
\hline $7 a$ & $2.93 / 1.32$ & 64 & 32 & 128 & 8 \\
\hline $7 \mathrm{~b}$ & $3.21 / 1.62$ & 128 & 32 & 128 & 8 \\
\hline $8 a$ & $3.4 / 1.79$ & 32 & 16 & 64 & 2 \\
\hline $8 b$ & $3.68 / 2.1$ & 128 & 32 & 128 & 8 \\
\hline $9 a$ & $3.1 / 1.36$ & 128 & 32 & 8 & 8 \\
\hline $9 b$ & $3.38 / 2.23$ & 64 & 64 & 8 & 8 \\
\hline $10 a$ & $2.38 / 1.89$ & 64 & 64 & 128 & 2 \\
\hline $10 \mathrm{~b}$ & $2.66 / 1.11$ & $>128$ & 32 & $>128$ & 2 \\
\hline $11 a$ & $2.55 / 1.03$ & 64 & 64 & $>128$ & 4 \\
\hline $11 b$ & $2.83 / 1.39$ & $>128$ & $>128$ & $>128$ & 32 \\
\hline $12 a$ & $2.71 / 2.21$ & 64 & 64 & $>128$ & 4 \\
\hline $12 b$ & $2.99 / 1.44$ & 64 & 64 & $>128$ & 8 \\
\hline $13 a$ & $2.36 / 1.86$ & 16 & 32 & 128 & 2 \\
\hline $13 b$ & $2.64 / 1.08$ & 32 & 32 & 128 & 2 \\
\hline $14 a$ & $2.22 / 1.73$ & 64 & $>128$ & $>128$ & 2 \\
\hline $14 b$ & $2.5 / 0.96$ & $>128$ & $>128$ & $>128$ & 2 \\
\hline $15 a$ & $1.27 /-0.47$ & $>128$ & $>128$ & 128 & 32 \\
\hline $15 b$ & $1.56 / 0.4$ & $>128$ & 128 & $>128$ & 64 \\
\hline $16 a$ & $1.18 / 0.68$ & $>128$ & 128 & 64 & 32 \\
\hline $16 b$ & $1.46 /-0.09$ & 128 & 128 & 64 & 16 \\
\hline $17 a$ & $0.58 /-0.12$ & 128 & 128 & 128 & 128 \\
\hline $17 b$ & $0.86 /-1.11$ & $>128$ & $>128$ & $>128$ & 128 \\
\hline Azitromicin & - & 4 & 4 & 16 & 0.25 \\
\hline
\end{tabular}


Table 2. Classification models for two definitions of active (YES) and inactive (NO) compounds, against M. catarrhalis, built in terms of calculated lipophilicity parameters

\begin{tabular}{|c|c|c|}
\hline Classification models by See5 & clogP & $\operatorname{clog} D_{7.5}$ \\
\hline $\mathrm{MIC} \leq 16 \mathrm{YES}$ & $\log \mathrm{P} \leq 1.56: \mathrm{NO}(6 / 1)^{(\mathrm{a})}$ & $\log D_{7.5} \leq 0.68: \mathrm{NO}(6 / 1)$ \\
\hline $\mathrm{MIC}>16 \mathrm{NO}$ & $\log P>1.56:$ YES $(24 / 1)$ & $\log \mathrm{D}_{7.5}>0.68:$ YES $(24 / 1)$ \\
\hline $\mathrm{MIC}<16$ YES & $\log P \leq 1.56: \mathrm{NO}(9 / 3)$ & $\log \mathrm{D}_{7.5} \leq 0.30: \mathrm{NO}(9 / 3)$ \\
\hline $\mathrm{MIC} \geq 16 \mathrm{NO}$ & $\log P>1.56:$ YES $(21 / 0)$ & $\log D_{7.5}>0.30:$ YES $(21 / 0)$ \\
\hline
\end{tabular}

The lipophilic character of compounds has been found to be important parameter for the observed activity of the tested benzoimidazole derivatives against Moraxella catarrhalis. In general, the compounds with clogP $>1.56$ and $\log \mathrm{D}_{7.5}>0.68$ showed noteworthy antibacterial activity $(\leq 16 \mu \mathrm{g} / \mathrm{mL}$ ) against Moraxella catarrhalis (Table 2). These results are in agreement with previous findings which suggested increased susceptibility of Moraxella catarrhalis to hydrophobic agents. ${ }^{[36]}$ The observed relationship is probably associated with more efficient intracellular partitioning of active compounds.

The outer membrane of gram-negative bacteria is composed of lipopolysaccharide molecules (LPS) that form a hydrophilic environment providing protection against hydrophobic molecules. [37] Additionally, cells of Moraxella catarrhalis have on their surface low molecular weight lipooligosaccharides (LOS) instead of LPS which contribute to the increased hydrophobicity of its outer membrane. Consequently, more lipophilic molecules may show distinct antimicrobial activity against Moraxella catarrhalis as a result of higher cellular uptake.

\section{CONCLUSION}

In conclusion, a series of novel amidino substituted benzimidazole derivatives were designed and synthesized in good yields. A convenient and efficient synthetic route was applied starting from commercially available different heterocyclic aldehydes and all new compounds were characterized by ${ }^{1} \mathrm{H}$ NMR, ${ }^{13} \mathrm{C}$ NMR and elemental analysis. The in vitro antimicrobial activities of newly prepared benzimidazole derivatives were evaluated against four bacterial strains.

All tested compounds except compounds $17 \mathrm{a}$ and 17b inhibited the growth of human respiratory tract pathogen Moraxella catarrhalis. The lipophilic character of compounds has been found to be related to the observed activity of the tested benzimidazole derivatives against MoraxeIla catarrhalis. The compounds with clogP > 1.56 and $\operatorname{clog} \mathrm{D}_{7.5}>0.68$ showed antibacterial activity against Moraxella catarrhalis. The analysis of antibacterial, clogP and $\log \mathrm{D}$ results revealed that the most promising compound is the one with the fused heterocyclic group at 2-position of amidino substituted 1-methylindol-2-yl derivative 13a. Moreover compound 13a exhibited potent antibacterial activity towards Staphylococcus aureus and Moraxella catarralis. Furthermore, the SAR results obtained in this study will be applied for the further optimization of this heteroaromatic core and for the design of novel derivatives in order to improve initially observed antibacterial activity.

Acknowledgment. This work has been supported in part by Croatian Science Foundation under the project 5596 entitled Synthesis and cytostatic evaluations of novel nitrogen heterocycles library.

Supplementary Information. Supporting information to the paper is attached to the electronic version of the article at: http://doi.org/10.5562/cca3147.

\section{REFERENCES}

[1] R. Karalusa, A. Campagnari, Microbes Infect. 2000, 2, 547.

[2] S. P. W. De Vries, M. J. Eleveld, P. W. M. Hermans, H. J. Bootsma, PLoS One 8, 2013, e71293.

[3] Y. C. Su, B. Singh, K. Riesbeck, Future Microbiol., 2012, 7, 1073.

[4] R. lemura, T. Kawashima, T. Fukuda, K. Ito, G. Tsukamoto, J. Med. Chem. 1986, 29, 1178.

[5] M. Tonelli, F. Novelli, B. Tasso, I. Vazzana, A. Sparatore, V. Boido, F. Sparatore, P. La Colla, G. Sanna, G. Giliberti, B. Busonera, P. Farci, Bioorg. Med. Chem. 2014, 22, 4893.

[6] Y. F. Li, G. F. Wang, P. L. He, W. G. Huang, F. H. Zhu, H. Y. Gao, W. Tang, Y. Luo, C. L. Feng, L. P. Shi, Y. D. Ren, W. Lu, J. P. Zuo, J. Med. Chem. 2006, 49, 4790. 
[7] Y. S. Tong, J. J. Bouska, P. A. Ellis, E. F. Johnson, J. Leverson, X. S. Liu, P. A. Marcotte, A. M. Olson, D. J. Osterling, M. Przytulinska, L. E. Rodriguez, Y. Shi, N. Soni, J. Stavropoulos, S. Thomas, C. K. Donawho, D. J. Frost, Y. Luo, V. L. Giranda, T. D. Penning, J. Med. Chem., 2009, 52, 6803.

[8] K. C. S. Achar, K. M. Hosamani, H. R. Seetharamareddy, Eur. J. Med. Chem. 2010, 45, 2048.

[9] T. Kálai, M. Balog, A. Szabó, G. Gulyás, J. Jekő, B. Sümegi, K. Hideg, J. Med. Chem. 2009, 52, 1619.

[10] H. Göker, S. özden, S. Yildiz, D. W. Boykin, Eur. J. Med. Chem. 2005, 40, 1062.

[11] R. Morphy, Z. Ranković, J. Med. Chem. 2005, 48, 6523.

[12] B. Meunier, Acc. Chem. Res. 2008, 41, 69.

[13] J. Xie, C. T. Seto, Bioorg. Med. Chem. 2007, 15, 458.

[14] I. S. Krishnanjaneyulu, G. Saravanan, J. Vamsi, P. Supriya, J. U. Bhavana, M. V. Sunil Kumar, J. Adv. Pharm. Technol. Res. 2014, 5, 21.

[15] A. Patel, H. J. Smith, J. Sturzebecher, in Introduction to the Principles of Drug Design and Action (Ed.: H. J. Smith) Harwood Academic Publishers, 2005.

[16] C. Marzano, S. M. Sbovata, F. Bettio, R. A. Michelin, R. Seraglio, T. Kiss, A. Venzo, R. Bertani, J. Biol. Inorg. Chem. 2007, 12, 477.

[17] Z. Y. Liu, T. Wenzler, R. Brun, X. Zhu, D. W. Boykin, Eur. J. Med. Chem. 2014, 83, 167.

[18] N. Gelus, C. Bailly, F. Hamy, T. Klimkait, W. D. Wilson, D. W. Boykin, Bioorg. Med. Chem. 1999, 7, 1089.

[19] V. A. Glushkov, L. V. Anikina, V. Vikharev, B. Yu. E. V. Feshina, Yu. V. Shklyaev, Pharm. Chem. J. 2005, 39, 533.

[20] S. M. Sondhi, J. Singh, A. Kumar, H. Jamal, P. P. Gupta, Eur. J. Med. Chem. 2009, 44, 1010.

[21] W. Treesuwan, K. Wittayanarakul, N. G. Anthony, G. Huchet, H. Alniss, S. Hannongbua, A. I. Khalaf, C. J. Suckling, J. A. Parkinson, S. P. Mackay, Phys. Chem. Chem. Phys. 2009, 11, 10682.

[22] K. Starčević, M. Kralj, K. Ester, I. Sabol, M. Grce, K. Pavelić, G. Karminski-Zamola, Bioorg. Med. Chem. 2007, 15, 4419.

[23] K. Starčević, M. Kralj, I. Piantanida, L. Šuman, K. Pavelić, G. Karminski-Zamola, Eur. J. Med. Chem. 2006, 41, 925.
[24] M. Hranjec, M. Kralj, I. Piantanida, M. Sedić, L. Šuman, K. Pavelić, G. Karminski-Zamola, J. Med. Chem. 2007, 50, 5696.

[25] K. Starčević, G. Karminski-Zamola, I. Piantanida, M. Žinić, L. Šuman, M. Kralj, J. Am. Chem. Soc. 2005, 127, 1074.

[26] Methods for Dilution Antimicrobial Susceptibility Tests for Bacteria that Grow Aerobically. M07eA8, Clinical Laboratory Standard Institute CLSI, Wayne, PA, 2009.

[27] A. Lee, W. Mao, M. S. Warren, A. Mistry, K. Hoshino, R. Okumura, H. Ishida, O. Lomovskaya, J. Bacteriol. 2000, 2182, 3142.

[28] D. A. Filimonov, V. V. Poroikov, In Chemoinformatics Approaches to Virtual Screening, (Eds.; A. Vamek, A. Tropsha) RSC Publishing: Camebridge, UK, 2008, p. 182.

[29] A. Lagunin, D. Filimonov, V. Poroikov, Curr. Pharm. Des. 2010, 16, 1703.

[30] G. Cruciani, P. Crivori, P. A. Carrupt, B. Testa, J. Mol. Struct. Theochem. 2000, 503, 17.

[31] J. R. Quinlan, C4.5: Programs for Machine Learning; Morgan Kaufmann Publishers, Inc.: San Mateo, CA, 1993.

[32] J. R. Brannon, D. L. Burk, J. M. Leclerc, J. L. Thomassin, A. Portt, A. M. Berghuis, S. Gruenheid, H. Le Moual, Infect. Immun. 2015, 83, 2300.

[33] L. Racané, S. Kraljević Pavelić, R. Nhili, S. Depauw, C. Paul-Constant, I. Ratkaj, M. H. David-Cordonnier, V. Tralić-Kulenović, G. Karminski-Zamola, Eur. J. Med. Chem. 2014, 86, 406.

[34] A. Lansiaux, L. Dassonneville, M. Facompre, A. Kumar, C. E. Stephens, M. Bajić, F. Tanious, W. D. Wilson, D. W. Boykin, C. Bailly, J. Med. Chem. 2002, 45, 1994.

[35] V. Stepanić, S. Koštrun, I. Malnar, M. Hlevnjak, K. Butković, I. Ćaleta, M. Dukši, G. Kragol, O. Makaruha-Stegić, L. Mikac, J. Ralić, I. Tatić, B. Tavčar, K. Valko, S. Zulfikari, V. Munić, J. Med. Chem. 2011, 54, 719.

[36] N. Gotoh, S. Tanaka, T. Nishino, FEMS Microbiol. Lett. 1989, 50, 211.

[37] H. Tsujimoto, N. Gotoh, T. Nishino, J. Infect. Chemother. 1999, 5, 196. 